\title{
Hostility and the heart
}

\author{
It's the hostility in type A personality that matters, but which element of hostility?
}

$\mathrm{T}$ he links between personality and coronary heart disease have challenged investigators ever since Friedman and Rosenman first suggested that the disease was more common among people with a type A personality-time pressured, competitive, and aggressive. ${ }^{1}$ The research has tried to improve clinicians' ability to predict who is most vulnerable to coronary heart disease and so to identify people who are most likely to benefit from prevention measures. One result of this research was recently summarised in a meta-analysis by Miller et al which showed that hostility is an independent risk factor for coronary heart disease. ${ }^{2}$

Hostility is a broad concept. It has connotations of anger, aggression, and a chronic negative outlook and so encompasses feelings, overt actions, and thoughts or attitudes. ${ }^{3}$ The cognitive components (those involving thoughts and attitudes) may include cynicism or mistrust, a desire to oppose others, or a wish to do them harm. ${ }^{4}$ A distinction should be drawn between the experience of hostility and its expression. ${ }^{5}$ The experience of hostility is subjective, perhaps including angry feelings or suspicious, cynical thoughts. Expressive or behavioural hostility implies observable acts of aggression, which may be verbal (for example, insults) or physical (for example, punching). ${ }^{5}$

Though these different components of hostility are conceptually distinct, they are difficult to distinguish clearly on research measures. ${ }^{25}$ This is partly because the various aspects are correlated: the experience of anger is often related to its expression. In addition, each separate measure may assess more than one aspect of hostility. ${ }^{3}$ For instance, a measure may address both the extent of a person's cynical attitude and his or her experience of angry feelings. Instruments measuring hostility do, however, vary in their emphasis on particular components. Measures such as the Cook-Medley hostility scale ${ }^{6}$ centre on the experiential, cognitive, cynical aspects, as do many other self report questionnaires. Assessments of hostility based on a standard interview seem, by contrast, to emphasise the observable, expressive, elements. ${ }^{5}$

These overt aspects of hostility have generally had the strongest association with coronary heart disease. ${ }^{2}$ In keeping with earlier reviews, ${ }^{7}$ Miller et al found that expressive hostility was independently associated with objective evidence of coronary heart disease such as confirmed myocardial infarction. ${ }^{2}$ Measures of experiential (cognitive) hostility had slightly weaker correlations with coronary heart disease and were more often associated with subjective evidence of coronary heart disease such as self reported chest pain. Hostility has been found to have associations with other cardiovascular risk factors such as cigarette smoking and alcohol consumption, ${ }^{8}$ but the results of the meta-analysis by Miller et al remained the same after controlling for these factors. ${ }^{2}$ Furthermore, the statistical techniques used allowed for weighting of studies according to the strength of design with greater weight given, for example, to prospective population based studies.

In general studies of the extent of the effect of hostility on the outcome of acute myocardial infarction (fatal and non-fatal) have been in line with those reported in 1995 by Barefoot et al, who found a multiple adjusted relative risk of 1.56 on acute myocardial infarction for an increase in the hostility score of two standard deviations. ${ }^{9}$ Comparisons with physical risk factors are difficult-as is shown by the diversity of study designs and statistical procedures. However, Barefoot et al used definitions of disease and statistical methods ${ }^{9}$ similar to those of Jensen et al, who reported a (multiply adjusted) relative risk of acute myocardial infarction in the highest versus the lowest quartiles of plasma cholesterol concentrations as $2.8 .^{10}$ For systolic blood pressure the comparable risks were 3.1 (untreated) and 2.0 (treated), and for smoking $30 \mathrm{~g}$ of tobacco/day versus non-smoking the relative risk was 2.8. Recently, Kawachi et al reported a relative risk 2.66 for the effect of anger on coronary heart disease, though the outcome measure included angina pectoris as well as acute myocardial infarction. ${ }^{11}$

In their meta-analysis Miller and colleagues acknowledged that this current work investigating the links between hostility and coronary heart disease has its foundations in the research of Friedman and Rosenman into type A behaviour. ${ }^{1}$ This concept was studied extensively from the 1960s onward and became very well known to the general public as well as to research workers. Gradually, however, the emphasis has moved to hostility since the results have shown repeatedly that it was the hostility element of the type A pattern that was the "toxic" component related to coronary heart disease. ${ }^{7} 12-14$ The question that now has to be answered is which component of hostility is most strongly and consistently associated with coronary heart disease. ${ }^{2}$

If we are to advance our understanding of the effects of hostility on coronary heart disease we shall have to pay closer attention to definitions and measurements and also to underlying physiological mechanisms. ${ }^{24}$ In the meantime, trying to avoid 
coronary heart disease gives us another good reason to be nice to one another.

\section{Martha C Whiteman Research associate \\ F Gerald R Fowkes Professor of epidemiology}

Wolfson Unit for the Prevention of Peripheral Vascular Diseases, Department of Public Health Sciences, University of Edinburgh, Edinburgh EH8 9AG

\section{Ian J Deary Professor of differential psychology \\ Department of Psychology, University of Edinburgh, Edinburgh EH8 9JZ \\ Martha Whiteman is supported by the British Heart Foundation}

1 Friedman M, Rosenman R. Association of specific overt behavior pattern with blood and cardiovascular findings. JAMA 1959;12:1286-96.

2 Miller TQ, Smith TW, Turner CW, Guijarro ML, Hallet AJ. A meta-analytic review of research on hostility and physical health. Psychol Bull 1996;119:322-48.

3 Barefoot JC. Developments in the measurements of hostility. In: Friedman HS, ed. Hostility, coping and health. Washington DC: APA, 1992.

4 Smith TW. Concepts and methods on the study of anger, hostility and health. In: Siegman AW, Smith TW, eds. Anger, hostility and the heart. Hillsdale, NJ: Erlbaum, 1994: 23-42.
5 Siegman AW. From type A to hostility to anger: reflections on the history of coronary-prone behavior. In: Siegman AW, Smith TW, eds. Anger, hostility and the heart. Hillsdale, NJ: Erlbaum, 1994: 1-21.

6 Cook W, Medley D. Proposed hostility and pharisaic-virtue scales for the MMPI. J Appl Psychol 1954;38:414-8.

7 Booth-Kewley S, Friedman HS. Psychological predictors of heart disease: A quantitative review. Psychol Bull 1987;101:343-62.

8 Whiteman MC, Fowkes FGR, Deary IJ, Lee AJ. Hostility, cigarette smoking and alcohol consumption in the general population. Soc Sci Med 1997;44:1089-96.

9 Barefoot JC, Larsen L, von der Lieth L, Schroll M. Hostility, incidence of acute myocardial infarction, and mortality in a sample of older Danish men and women. Am J Epidemiol 1995;142:477-84.

10 Jensen G, Nyboe J, Appleyard M, Schnohr P. Risk factors for acute myocardial infarction in Copenhagen II: Smoking, alcohol intake, physical activity, obesity, oral contraception, diabetes, lipids and blood pressure. Eur Heart J 1991;12:298-308.

11 Kawachi I, Sparrow D, Vokonas PS, Weiss ST. Symptoms of anxiety and risk of coronary heart disease: the normative aging study. Circulation 1996;5:2225-9.

12 Dembroski TM, Costa PT. Coronary-prone behavior: components of the type A pattern and hostility. J Pers 1987; 55:211-35.

13 Deary IJ, Fowkes FGR, Donnan PT, Housley E. Hostile personality and risks of peripheral arterial disease in the general population. Psychosom Med 1994;56:197-202.

14 Johnston DW. The current status of the coronary-prone behavior pattern. J Roy Soc Med 1993; 86:406-9.

\title{
Consent for transfusion
}

\author{
A duty of care
}

A 11 patients have the legal and ethical right before they agree to treatment to receive adequate information on the aims, benefits, and risks of the treatment. In Britain this is firmly stated in the patient's charter, as well as being highlighted by the Medical Defence Union ${ }^{1}$ and the Medical Protection Society $^{2}$ in their publications. It is also emphasised as a doctor's duty by the General Medical Council: "In particular as a doctor you must give patients information in a way they can understand; respect the rights of patients to be fully involved in decisions about their care."3 During most transactions between patients and doctors consent is implied, but when a procedure is likely to carry a substantial or material risk the right is usually interpreted as asking patients to provide express written consent. In the United Kingdom, unlike the United States, consent for the transfusion of blood and blood products is not independently sought and remains part of general consent.

Specialists in haematology and blood transfusion have, during the past two to three years, argued about the necessity of following the American lead and obtaining formal express consent for the transfusion of blood and blood products. The controversy does not hinge on the need to inform patients adequately-that is accepted-but centres on two issues. The first is whether consent in this instance is appropriate-that is, does transfusion of blood and blood products carry a material risk? The second is whether the consent obtained would be valid.

How is material risk defined? In the case of Sidaway $v$ Bethlem Royal Hospital ${ }^{4}$ the Law Lords, Britain's supreme court of appeal, made it clear that it was for the medical profession to define material risk. In reaching a decision, consideration should be given not only to the quantity but also to the nature of the risk. Minor clinically insignificant reactions to transfusion occur fairly commonly, whereas the risks of complica- tions with serious or fatal long term consequences are low and therefore could be said to obviate the need for express consent. But should the profession avoid its traditionally paternalistic stance and consider the problem more from the point of view of the prudent patient? As stated in Canterbury $v$ Spence: "A risk is ... material when a reasonable person, in what the physician knows or should know to be the patient's position, would be likely to attach significance to the risk or cluster of risks, in deciding whether or not to forego the proposed therapy." In imparting any information to patients, care must be taken also to discuss the balance of risks-the risk of receiving a transfusion against the risk of not being transfused.

Are the difficulties related more to the consideration of whether consent obtained would be valid? True or valid consent does not need to be written, but it must be based on adequate information that the patient can understand, and it must be obtained without coercion. Would these requirements be satisfied in the likely situation of the task being delegated to the least experienced member of the team, often working in difficult circumstances? The profession's anxieties therefore centre on the logistics and mechanics of obtaining the consent-who should obtain consent and when. ${ }^{6}$ In any instance, it is essential that a patient does not decide against a transfusion inappropriately.

How is the question to be resolved? Blood and blood products are a human resource, and, despite the best efforts of the transfusion service, they continue to carry an unknown and indeed an unknowable risk. The answer might lie in a combination of initiatives that have already begun but are slow to progress. These include better audit of transfusion practice, better information about clinically significant risk, and better education of the nursing and medical professions in the use of blood and blood products. Consideration should also be given to delegating the supervision of 
blood transfusion, including obtaining consent, to specially trained nurse transfusionists. Finally, there should be better communication between the legal and medical professions. ${ }^{7}$ These initiatives would permit a greater knowledge and understanding of the issues, the

1 Medical defence Union. Consent to treatment. London: MDU, 1992.

Medical Protection Society. Consent and comfidentiality. London: MPS, 1991.

3 General Medical Council. The duties of a doctor. guidance from the General Medical Council. London: GMC, 1995. evolution of a reasoned decision, and the fulfilment of all doctors' unchallenged duty of care to their patients. F G Williams Director

Welsh Blood Service, Ely Valley Road, Talbot Green Pontyclun, Cardiff CF72 9WB

\title{
Developing high quality clinical databases
}

\author{
The key to a new research paradigm
}

See $p 388$

A lthough it is almost 20 years since Arnold Relman heralded the dawning of the "era of assessment and accountability," we still cling largely to a traditional research paradigm based on ad hoc studies. We do this despite well recognised limitations: such studies are expensive, and so only a limited range of interventions have been, and can ever be, investigated; the rapidity with which health technologies evolve means study results may be of no practical value by the time they are obtained; the results are often of uncertain generalisability as they tend to be carried out in atypical settings; the participating clinicians often have little sense of ownership; and small samples restrict the scope for subgroup analyses and thus the practical value of the results.

High quality clinical databases offer an alternative approach, with the potential to bring research closer to practice and audit. The advantages include wide ownership and high generalisability through the participation of many clinicians; relatively low cost for each study, as the expense of data collection is spread over a range of research, audit, and administrative uses; the ability to generate large samples rapidly; the opportunity to study rare conditions or interventions; and the provision of accurate information for clinical practice, audit, and administration. Databases can be used either for non-randomised analyses or to generate hypotheses and provide ready access to clinicians prepared to participate in randomised trials. ${ }^{2}$

The benefits of developing high quality clinical databases have long been recognised. Almost 100 years ago, surgeons on both sides of the Atlantic called for routine documentation of clinical practice. In 1907 Ernest Groves, a Bristol surgeon, suggested standardising clinical terminology and measurement, ${ }^{3}$ while in Boston Ernest Codman had the temerity to establish an End Results Hospital in which outcome one year after surgery was routinely assessed and recorded. ${ }^{4}$ However, he failed to persuade his colleagues to adopt the same approach and, until recently, little progress had been made with this strategy.

While lack of progress has partly been a consequence of a lack of interest on the part of clinicians, managers, and researchers, it has also reflected the demanding requirements for creating a high quality database. If the benefits are going to be realised, such databases must include individual data on all consecutive cases, use standard definitions of conditions and outcomes, ensure data are complete and accurate, and include data on all known patient characteristics that affect outcome. Anyone familiar with routine hospital information systems, designed for administrative purposes, will appreciate that they fail to meet these requirements.

With developments in information technology, the call for new, carefully designed and managed clinical systems is no longer fanciful. Indeed, in Britain some groups of clinicians have already made considerable progress. Surgeons throughout Lothian, Scotland, established a system in the $1970 \mathrm{~s}^{5}$; obstetricians in North West Thames region did so in the $1980 \mathrm{~s}^{6}$; and haematologists, first in North West and Northern regions $^{7}$ and later in other regions, have established a leukaemia register, pioneered by Stephen Proctor in Newcastle, (page 388). ${ }^{8}$ However, the most ambitious development has occurred in intensive care. Encouraged by its work validating a risk adjustment model (APACHE II), the British Intensive Care Society is establishing a national database for audit and research. ${ }^{9}$

While other groups can learn much from the experiences of the pioneers in this area, it is likely that no single model for organising and managing high quality clinical databases will be appropriate in all circumstances. Databases for long term treatment will differ from those for one off treatments, and the requirements for common, low cost treatments will differ from those for rare, expensive interventions. Regardless of which approach is adopted, early experiences suggest clinical and scientific credibility are more likely if clinicians and health services researchers collaborate in the design, management, and use of the database.

Apart from extending this approach to other clinical areas, ${ }^{10}$ what other challenges lie ahead for the users of these databases? First, as with any non-randomised comparisons, an accurate method for risk adjustment is needed if meaningful results are to be obtained. While considerable progress has been made in some areas (such as intensive care), in other areas work has barely commenced. Second, the research and audit potential of clinical databases could be enhanced by linking to other databases. For example, the geographical and socioeconomic equity of services could be evaluated by linking to census data. ${ }^{2}$ While such developments will enhance their value, the biggest 
challenge remains getting the databases established, a task that requires clinical knowledge, health services research skills, political nous, and much ingenuity.

Nick Black Professor of health services research

Department of Public Health and Policy, London School of Hygiene and Tropical Medicine, London WC1E 7HT

Relman AS. Assessment and accountability. The third revolution in medical care. N Engl J Med 1988;319:1220-2.

2 Black NA. A regional computerised surgical audit project. Qual Assur Health Care 1990;2:263-70.

3 Groves EWH. Surgical statistics: a plea for a uniform registration of operation results. BMJ 1908;ii:1008-9.
4 Donabedian A. The end result hospital: Ernest Codman's contribution to quality assessment and beyond. Milbank Q 1989;67:233-56.

5 Gruer R, Gordon DS, Gunn AA, Ruckley CV. Audit of surgical audit. Lancet 1986;i:23-7.

6 Patterson CM, Chapple JC, Beard RW, Joffe M, Steer PJ, Wright CSW. Evaluating the quality of maternity services-a discussion paper. $\mathrm{Br} J$ Obstet Gynaecol 1991;98:1073-8.

7 Charlton BG, Taylor PRA, Proctor SJ. The PACE (population-adjusted clinical epidemiology) strategy: a new approach to multi-centred clinical research. QJ Med 1997;90:147-51

8 Interview with Stephen Proctor. BMJ 1997;315:388

9 Rowan KM. Intensive Care Society has set up a centre for national audit [letter]. BMJ 1996;313:1007-8.

10 Sochart DH, Long AJ, Porter ML. Joint responsibility: the need for a national arthroplasty register [editorial]. BMJ 1996;313:66-7.

\title{
Do professions have a future?
}

\author{
Perhaps, if they are not defensive or complacent
}

W ithin the medical profession a perception exists of a growing gap between the providers and users of health care and, more generally, between the health professions and society. The commitment to serve society, a key attribute of all professions, has been questioned from within and outside the ranks of medicine, and the medical professions' powers and privileges of self regulation have been

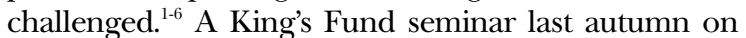
the future of the professions brought together a range of perspectives, including views from architecture, nursing, medicine, and politics.

Central to the implicit bargain between the profession and society is the exchange of privileges (self regulation and the control of training) in return for the trustworthy fulfilment of a role that society recognises as valuable. As with individuals, so with professions, there is an inherent tendency to behave both selfishly (through self interest and preservation) and unselfishly (through disinterested, conscientious service of others). Not surprisingly, the interests of both society and the profession are best served when these tendencies coincide. Perhaps medicine is still viewed as the archetypal profession because in general doctors have been able to serve their patients and enjoy substantial privileges without apparent conflict.

That position may no longer be tenable. The consensus at the King's Fund conference was that the medical profession needs to respond to the challenges of increased patient demand in a climate of limited healthcare spending and to greater calls for accountability and transparency in its professional affairs. A complacent, defensive, or nostalgic stance by the profession will not serve.

What aspects of the professional bargain need to be reviewed? First is the responsibility to the patient on the one hand and society on the other for managing limited resources. The traditional British compromise of implicit rationing by doctors is becoming increasingly uncomfortable. The profession, the state, and the public need to examine the alternatives. If the NHS cannot provide everything that every patient wants, and which offers benefit, the task of squaring the circle cannot be left to the physician unaided and unseen.

Secondly, for self regulation by the medical profession to survive it must be effective, transparent, and demonstrably in the public interest. Initiatives by the General Medical Council are a positive step but they must not stop there. The GMC needs to show its effectiveness in ensuring competence, not merely in policing flagrant lapses in behaviour. The royal colleges and the BMA also have roles-for example, ensuring good standards of care at all hours despite the long overdue reduction in junior doctors' hours and the recent changes in general practice.

Thirdly, medicine must be more willing to develop partnerships with the other caring professions and allow greater flexibility in working practices to improve the delivery of patient care. The demarcation lines between medicine and its partners are rapidly changing, and institutions such as the royal colleges have lagged behind in their response. The public's increasing attachment to alternative medicine suggests that more serious attention should be given to its potential contributions. These developments pose no serious threat to medicine's monopoly over its core roles and are being embraced by many doctors.

Fourthly, generational differences are emerging between cohorts of doctors in their attitudes toward a host of issues facing the profession, such as the role of doctors in NHS management and approaches to multidisciplinary care. ${ }^{8}$ Medical leaders need to face up to these changes and the societal trends transforming all occupational groups.

\section{Julia Abelson Researcher}

School of Social Sciences, University of Bath, Bath BA2 7AY

P H Maxwell Honorary consultant nephrologist

Churchill Hospital, Oxford OX3 7LJ

R J Maxwell Chief Executive Officer

Kings Fund, London W1M 0AN

1 The Times. "Profession afoul?" 1992; 3 Feb: 13a

2 Armstrong D. "Medicine as a profession: times of change". BMJ 1990; 301:691-3.

3 Calman K. The profession of medicine. BMJ 1994;309:1140-3

4 Morrison I, Smith R. The future of medicine: brighter than you might think. BMJ 1994:309:1099-1100.

5 Shock M. Medicine at the centre of the nation's affairs. BMJ 1994; 309:1730-3.

6 Short J. Has nursing lost its way? Dual perspective. BMJ 1995;311:303-4.

7 General Medical Council. The duties of a doctor. London: GMC. 1995.

8 British Medical Association. Core values of the medical profession in the 21st century-survey report. London: BMA, 1995.

9 British Medical Association. BMA cohort study of medical graduates: first report (Part II)-professional values. London: BMA, 1995. 